\title{
Surface Free Energy Components of Glass from Ellipsometry and Zeta Potential Measurements
}

\author{
E. CHIBOWSKI, ${ }^{*}$ L. HOLYSZ, $*$ G. A. M. KIP, $\dagger$ A. VAN SILFHOUT, $\dagger$ \\ AND H. J. BUSSCHER +1 \\ * Department of Physical Chemistry, Institute of Chemistry, Maria Curie-Skłodowska University, 20-031 Lublin, \\ Poland; $\uparrow$ Department of Applied Physics, Twente University of Technology, P.O. Box 217, 7500 AE Enschede, \\ The Netherlands; and $\ddagger$ Laboratory for Materia Technica, University of Groningen, \\ Antonius Deusinglaan 1, 9713 AV Groningen, The Netherlands
}

Received June 9, 1988; accepted November 28, 1988

\begin{abstract}
Two different experimental approaches based on ellipsometry and zeta potential measurements have been employed to determine the dispersion and polar surface free energy components of glass. From ellipsometry the adsorption isotherms of $n$-octane and water have been determined, yielding values for the film pressures of $n$-octane and water and the dispersion and polar surface free energy components of glass. Similarly, zeta potentials in water of glass covered with various amounts of $n$-octane and $n$ hexanol have been determined. Next, the film pressures of these liquids and surface free energy components of glass were also calculated. Thus determined values are 32 and $80 \mathrm{~mJ} / \mathrm{m}^{2}$ (from ellipsometry) and 25 and $80 \mathrm{~mJ} / \mathrm{m}^{2}$ (from zeta potentials) for the dispersion and polar components, respectively. The correspondence between the surface free energies obtained by two completely independent methods gives confidence to the approaches employed. (C) 1989 Academic Press, Inc.
\end{abstract}

\section{INTRODUCTION}

Determination of solid surface free energies is still an open problem, both from a theoretical and from an experimental point of view. Very recently Spelt and Neumann (1) have questioned the validity of the additivity of the surface free energy components (2-5), maintaining that dispersion and nondispersion components have no physical meaning. Van Oss et al. (6), however, abandoning the equation of state approach proposed an alternative interpretation of the concept of dispersion and polar components, distinguishing Lifshitz-van der Waals (previously called dispersion) and acid-base interactions (included in the polar term). Despite the controversies lingering over surface free energy determinations, it appears that many physicochemical processes occurring at interfaces can be understood on the basis of experimentally obtained surface free

\footnotetext{
${ }^{1}$ To whom correspondence should be addressed.
}

energies, estimated according to one of the approaches available.

Another problem is how to interpret the interfacial solid-liquid or liquid-liquid interactions, whether they are equal to the geometric $(4,7)$, harmonic $(8)$, or even arithmetic (5) mean, or whether they can be expressed with the help of the Good interaction parameter (9). Generally, data to solve these type of problems are generated from contact angle measurements (10-13), adsorption isotherms $(5,14,15)$, zeta potentials as measured in specially chosen systems (16$19)$, and also ellipsometry $(20,21)$. The determination of solid surface free energies higher than those of water such as encountered for ionic crystals or glass (22) is especially a matter of much dispute, as it involves spreading pressure values, which cannot be neglected, as is usually done for low surface free energy materials $(23,24)$.

The aim of this paper was to compare the surface free energy components of glass, a high 
surface free energy material, as obtained from ellipsometrically determined adsorption isotherms and zeta potentials.

\section{EXPERIMENTAL}

Grains of glass powder (Smethwick, England) with a size distribution between 10 and $25 \mu \mathrm{m}$ (average diameter approximately $15 \mu \mathrm{m}$ ) and with a BET specific surface area of $1.08 \mathrm{~m}^{2} / \mathrm{g}$ were prepared by crushing and grinding of cleaned glass slips in a stainlesssteel ball mill. The reagents employed were $n$ octane from Merck (analytical grade) used in ellipsometric measurements and from Fluka $\mathrm{AG}$ (puriss) used in electrokinetic measurements; $n$-hexanol was from Reachim (USSR, pure). The water used for ellipsometry was of atomic absorption analysis grade, whereas doubly distilled water having a conductivity of 3-7 $\mu \mathrm{S} \mathrm{cm}^{-1}$ was employed for zeta potential measurements.

Water and $n$-octane adsorption isotherms on intact glass surfaces were measured ellipsometrically at $25^{\circ} \mathrm{C}$ as described in detail previously with a so-called null-type ellipsometer, equipped with a $6328-\AA$ wavelength laser (beam diameter $3 \mathrm{~mm}$ ) (21). Adsorption was carried out in a double-walled stainless-steel vacuum vessel in which the temperature was controlled within $0.05 \mathrm{~K}$ (for details see Ref. (21)). The pressure was less than 0.01 Torr for $1 \mathrm{~h}$ before the adsorption experiments started. The adsorbate pressure was governed by the temperature of a liquid reservoir connected to the adsorption chamber. Temperature variation of the reservoir enabled relative pressures up to 1.1. The absolute vapor pressure $P$ was measured with a differential pressure transducer against vacuum with an accuracy of 0.02 Torr.

In ellipsometry the reflection of monochromatic light at an interface is studied. The Fresnel reflection coefficients $r_{\mathrm{p}}$ and $r_{\mathrm{s}}$ (p for parallel and $s$ for the perpendicular components of the light with respect to the plane of incidence) can be determined relative to each other. The two measured ellipsometer param- eters $\Delta$ and $\psi$ are related to $r_{\mathrm{p}}$ and $r_{\mathrm{s}}$ by the equation

$$
\frac{r_{\mathrm{p}}}{r_{\mathrm{s}}}=\tan \psi \cdot \exp i \Delta
$$

in which $\tan \psi$ is the relative amplitude change and $\Delta$ is the change in the phase.

Reflection of light at a perfectly clean plane surface under vacuum gives the so-called clean surface values $\bar{\Delta}$ and $\bar{\psi}$. From these, the complex refractive index of the sample can be calculated.

Adsorption or other processes occurring at the surface will result in changes in $\Delta$ and $\psi$. For physisorption only and if the thickness of the adsorbed film $s_{\mathrm{f}}$ is much smaller than the wavelength of the light, the Drude approximation gives

$$
\delta \Delta=\Delta-\bar{\Delta}=-\chi \cdot s_{\mathrm{f}} .
$$

The constant $\chi$ is determined by the angle of incidence $\phi_{0}$, the refractive indices $n_{\mathrm{s}}, n_{\mathrm{v}}, n_{\mathrm{f}}$, and the wavelength $\lambda \cdot n_{\mathrm{v}}$ is almost equal to the refractive index of vacuum $n_{0}$. Thus Eq. [2] provides a means for calculating the adsorbed layer thickness.

$n$-Hexanol and $n$-octane adsorption isotherms were also determined on grains of glass by a more indirect technique based on zeta potentials (16-19). Briefly, the glass grains were heated to $480^{\circ} \mathrm{C}$ for $5 \mathrm{~h}$ and 0.15 -g aliquots were put in glass ampoules, which were subsequently cooled in liquid nitrogen. Using a Hamilton microsyringe (volume $1 \mu \mathrm{l}$ ) desired volumes of $n$-octane or $n$-hexanol were dosed onto the samples, which were then quickly sealed in a flame and heated at $130^{\circ} \mathrm{C}$ for $3 \mathrm{~h}\left(n\right.$-octane) and at $170^{\circ} \mathrm{C}$ for $3 \mathrm{~h}(n$ hexanol), shaken several times by hand, and cooled to $25 \pm 1^{\circ} \mathrm{C}$, i.e., the temperature of the measurements. One hundred milliliters of suspension was prepared from each thus treated sample in doubly distilled water and the electrophoretic velocity was determined. The average $\mathrm{pH}$ of the suspensions was 7.2 \pm 0.1 . The rectangular electrophoresis cell $(100 \times 20 \times 1 \mathrm{~mm} ; 10 \mathrm{~V} / \mathrm{cm}$ potential gra- 
dient and operated at a $210 \times$ magnification ) was filled twice with each suspension and approximately 25 particles were measured each time. Zeta potentials were calculated from the measured particle velocity by the Smoluchowski equation.

\section{RESULTS}

The thicknesses of the adsorbed water and $n$-octane films on the intact glass surfaces for various relative pressures $p / p_{0}$ at $298 \mathrm{~K}$ are listed in Tables I and II, respectively. As can be seen, the results at lower $p / p_{0}$ should be considered with caution as they are within the range of the approximate standard deviations. Using these values, the specific film volumes, $\mathrm{cm}^{3} / \mathrm{cm}^{2}$, were calculated and plotted versus relative pressures, thus obtaining adsorption isotherms. Then, $n$-octane and water film pressures were obtained from the equation of Bangham and Razouk (5) by graphical integration. Thus determined film pressures are plotted versus their specific film volumes in Figs. 1 and 2 for $n$-octane and water, respectively. The standard deviations in the derived film pressures are approximately $\pm 6 \%$, due to

\section{TABLE I}

Water Film Thickness on Glass as a Function of Its Relative Vapor Pressure

\begin{tabular}{cc}
\hline Relative pressure $p / p_{0}$ & Film thickness $(\AA)$ \\
\hline 0.290 & 0.2 \\
0.430 & 0.2 \\
0.525 & 1.3 \\
0.589 & 3.4 \\
0.650 & 5.1 \\
0.699 & 9.2 \\
0.744 & 10.6 \\
0.795 & 15.8 \\
0.842 & 21.2 \\
0.892 & 26.0 \\
0.907 & 29.3 \\
0.945 & 31.9 \\
0.989 & 44.9 \\
\hline
\end{tabular}

Note. SD in film thickness amounts approximately 2 $\tilde{A}$, arising from three different adsorption runs on various specimens.

Joumal of Colloid and Interface Science, Vol. 132, No. 1, October 1, 1989
TABLE II

n-Octane Film Thickness on Glass as a Function of Its Relative Vapor Pressure

\begin{tabular}{cc}
\hline Relative pressure $p / p_{0}$ & Film thickness $(\AA)$ \\
\hline 0.027 & 0.2 \\
0.060 & 0.2 \\
0.151 & 1.0 \\
0.200 & 1.7 \\
0.265 & 2.2 \\
0.303 & 2.3 \\
0.381 & 2.7 \\
0.408 & 3.0 \\
0.457 & 3.2 \\
0.519 & 3.9 \\
0.626 & 5.1 \\
0.722 & 6.0 \\
0.781 & 6.9 \\
0.805 & 7.4 \\
0.832 & 8.1 \\
0.862 & 9.2 \\
0.890 & 10.8 \\
0.905 & 12.5 \\
0.916 & 13.8 \\
0.946 & 16.4 \\
0.962 & 20.2 \\
0.974 & 20.7 \\
0.984 & 29.0 \\
1.000 & 57.4 \\
\hline
\end{tabular}

Note. SD in film thickness amounts approximately 2 $\AA$, arising from three different adsorption runs on various specimens.

the propagation of the errors in the film thicknesses. Moreover, calculated monomolecular layers of water and $n$-octane are also marked on the curves, assuming 7.06 and $45.36 \AA^{2}$ for the cross-sectional areas of water and $n$ octane molecules, respectively. From Fig. 1 it can be seen that ca. 13 monomolecular layers of $n$-octane can be adsorbed on the glass surface, whereas the film pressure remains constant already after adsorption of 5-6 monolayers. The total amount of adsorbed water corresponds to 15 statistical monolayers, which is in agreement with results found on quartz $(25,26)$. Both curves for water and $n$ octane demonstrate characteristic inflections, as can be seen in the figures. It should be noted that the exact identification of these inflections is a tedious procedure which should be done 


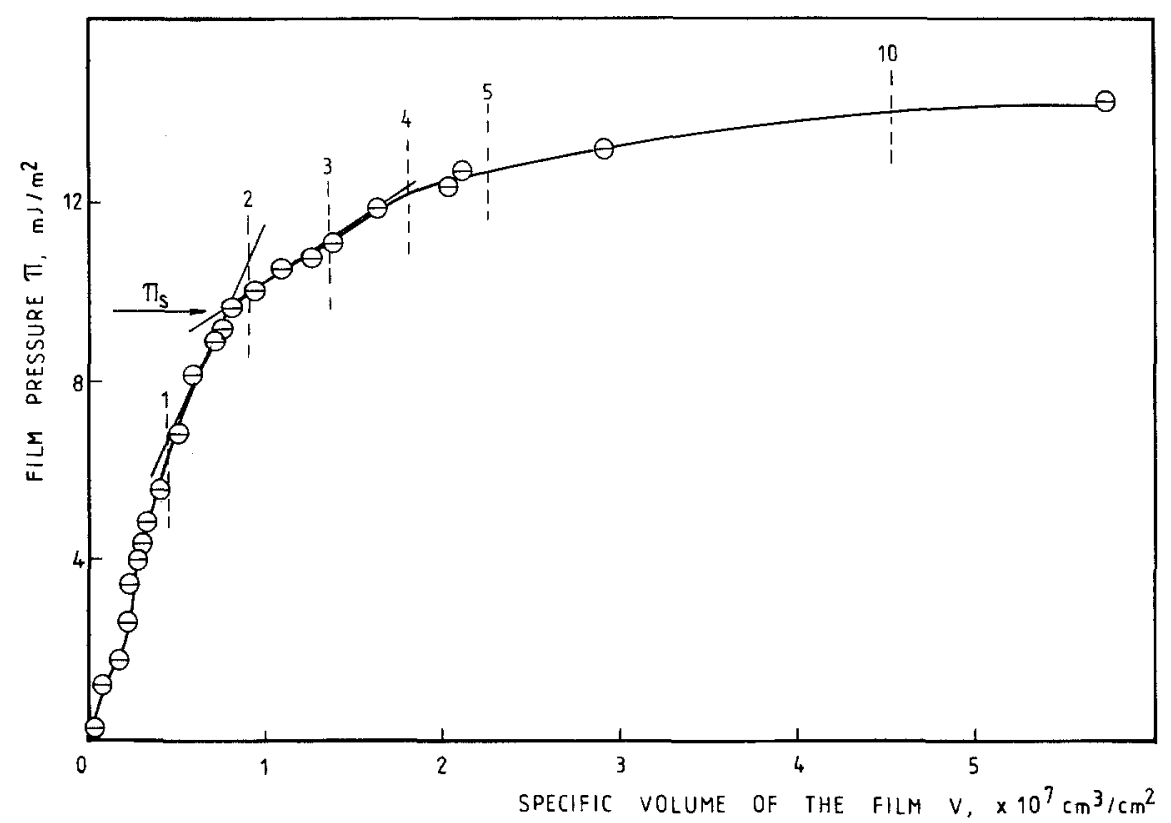

FIG. 1. $n$-Octane film pressure on glass $( \pm 6 \%)$ as a function of the specific volume of the film as obtained from ellipsometry. Calculated monomolecular layers are denoted on the curve.

with great care, also giving rise to an enlargement of the final errors in the derived quantities. In general, cusps have initially been identified by visual inspection of the curves, after which straight lines have been constructed by linear least-squares fits. By in-

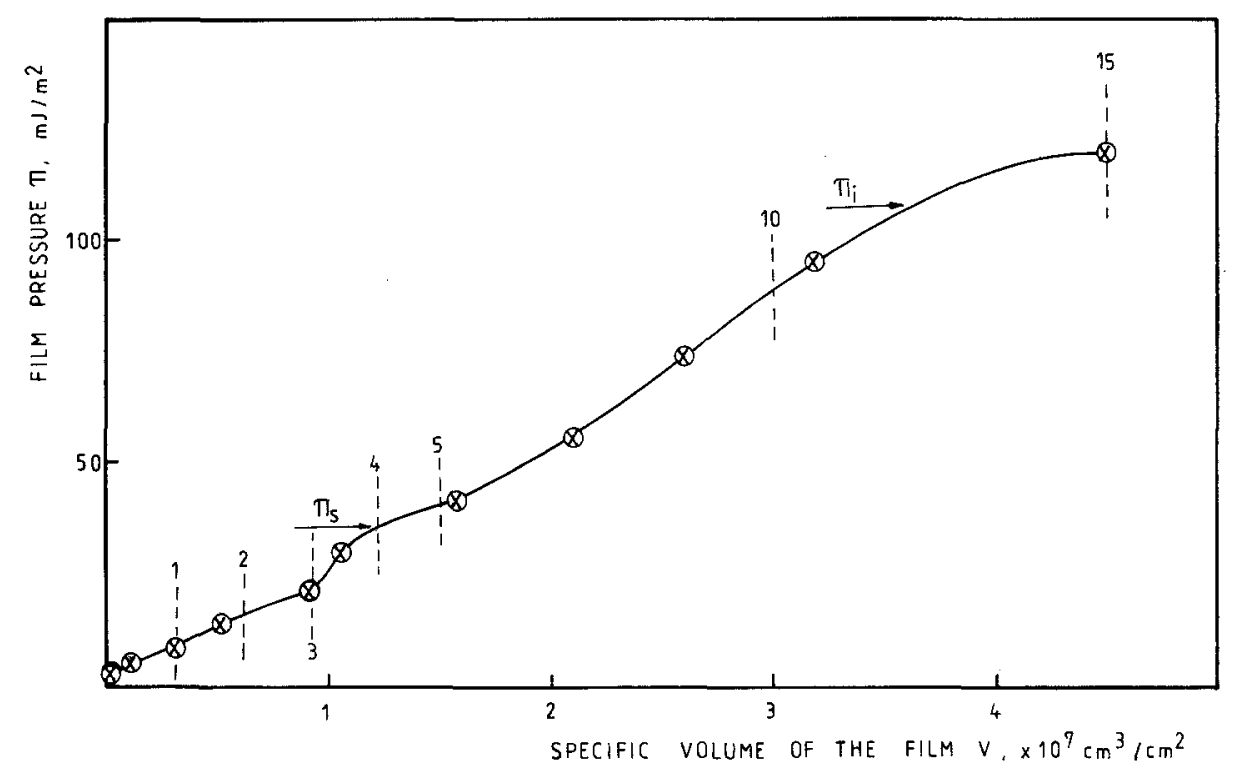

FIG. 2. Water film pressure on glass $( \pm 6 \%)$ as a function of the specific volume of the film as obtained from ellipsometry. Calculated monomolecular layers are denoted on the curve. $\pi_{\mathrm{i}}$ is the point of immersional wetting. 
creasing or decreasing the number of data points involved in a particular line segment, a final choice of exact position of the cusps was made. From our previous studies $(15,19$, 26 ) it can be deduced that the inflection near the second monolayer in Fig. 1 ( $n$-octane adsorption isotherm ) can be considered the point of spreading wetting, i.e.,

$$
\pi_{\mathrm{s}}=W_{\mathrm{s}}=10 \mathrm{~mJ} / \mathrm{m}^{2} .
$$

Employing this value of $\pi_{\mathrm{s}}=10 \mathrm{~mJ} / \mathrm{m}^{2}$, the dispersion part of the glass surface free energy, $\gamma_{\mathrm{g}}^{\mathrm{d}}$, can be calculated according to $(2,7)$

$$
\pi_{\mathrm{s}}=W_{\mathrm{s}}=-2 \gamma_{1}+2\left(\gamma_{1} \gamma_{\mathrm{g}}^{\mathrm{d}}\right)^{1 / 2},
$$

yielding $\gamma_{\mathrm{g}}^{\mathrm{d}}=32 \mathrm{~mJ} / \mathrm{m}^{2}$, where $\gamma_{\mathrm{l}}$ is the surface tension of $n$-octane. Having determined $\gamma_{\mathrm{g}}^{\mathrm{d}}$ and analyzing the $\pi$ changes in Fig. 2 for the adsorbed water film, one may estimate the polar (or rather more generally, nondispersion) component of the glass surface free energy from the inflection seen between the 3 rd and the 4th calculated monolayer of water. Taking the film pressure $\pi_{\mathrm{s}}=35 \mathrm{~mJ} / \mathrm{m}^{2}$ to be equal to the work of spreading, and $\gamma_{\mathrm{g}}^{\mathrm{d}}$ $=32 \mathrm{~mJ} / \mathrm{m}^{2}$, the polar component of the glass surface free energy can be calculated from

$$
\begin{aligned}
\pi_{\mathrm{s}}=W_{\mathrm{s}}=-2 \gamma_{\mathrm{w}}+2\left(\gamma_{\mathrm{w}}^{\mathrm{d}} \gamma_{\mathrm{g}}^{\mathrm{d}}\right)^{1 / 2} & \\
& +2\left(\gamma_{\mathrm{w}}^{\mathrm{p}} \gamma_{\mathrm{g}}^{\mathrm{p}}\right)^{1 / 2},
\end{aligned}
$$

yielding $\gamma_{\mathrm{g}}^{\mathrm{p}}=80 \mathrm{~mJ} / \mathrm{m}^{2}$, where $\gamma_{\mathrm{w}}^{\mathrm{d}}$ and $\gamma_{\mathrm{w}}^{\mathrm{p}}$ are the dispersion and polar components of the water surface free energy (21.8 and 51.0 $\mathrm{mJ} / \mathrm{m}^{2}$ respectively).

Zeta potential changes of glass grains in water are presented in Fig. 3 (top and bottom) as a function of the specific volume of adsorbed $n$-hexanol and $n$-octane, respectively. These curves are similar to those observed in other systems $(17,19)$. The calculated numbers of monolayers of $n$-hexanol ( $21 \AA^{2}$ crosssectional area) and $n$-octane $\left(45.36 \AA^{2}\right)$ are denoted in Fig. 3. Employing these results the film pressures $\pi$ were determined from the empiric relation and its graphical integration $(17,19)$ used earlier:

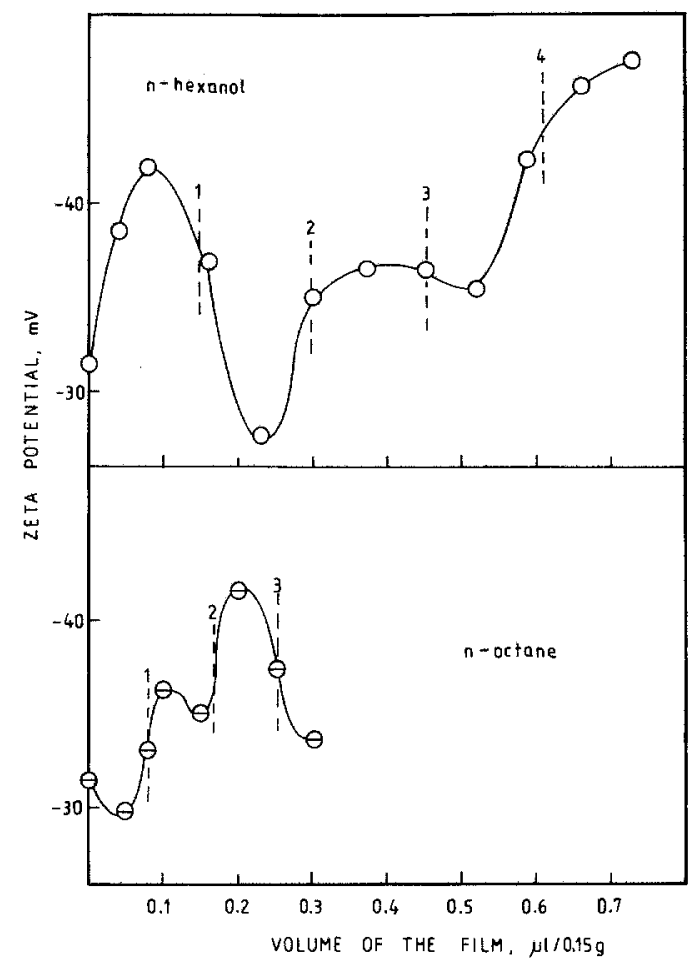

FIG. 3. Zeta potential changes ( $S D=2 \mathrm{mV}$ over 50 different particles) of glass grains in water, (top) for an adsorbed $n$-hexanol film and (bottom) for an adsorbed n-octane film.

$$
\pi=\frac{R T}{V_{0} A} \int_{\zeta_{0}}^{\zeta} v d(\ln \zeta)
$$

where $R, T$ are the gas constant and absolute temperature, $V_{0}$ is the molar volume of the adsorbed liquid, $A$ is the total surface of the sample used, $v$ is the film volume at which the zeta potential is $\zeta$ for the sample in water, and $\zeta_{0}$ is the zeta potential of the bare sample surface in water. Thus determined film pressures, with an estimated error of $7 \%$, due to the propagation of the errors in the zeta potentials are shown in Fig. 4 for $n$-octane and in Fig. 5 for $n$-hexanol against the number of the calculated monomolecular layers of the liquids.

From the inflection point in the $n$-octane adsorption isotherm near the second monolayer, we can derive $\pi_{\mathrm{s}}=3.5 \mathrm{~mJ} / \mathrm{m}^{2}$, which, together with Eq. [3], yields $\gamma_{\mathrm{g}}^{\mathrm{d}}$ equal to 25 $\mathrm{mJ} / \mathrm{m}^{2}$, which is somewhat lower than cal- 


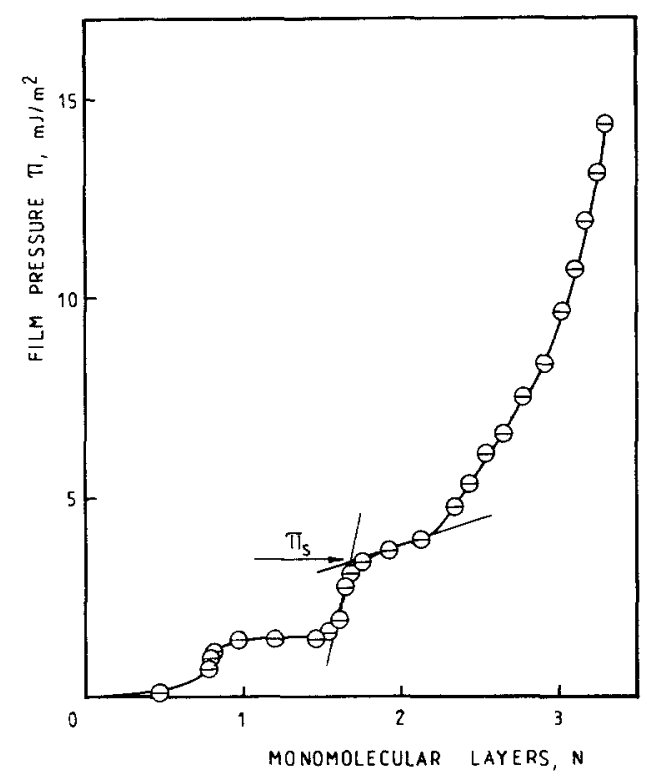

FIG. 4. $n$-Octane film pressure $( \pm 7 \%)$ on glass as a function of the number of calculated monomolecular layers determined from zeta potentials.

culated from Fig. 1, derived ellipsometrically. This difference is probably due to different amounts of preadsorbed water, present on the surfaces during the ellipsometric and electrokinetic experiments.

Figure 5 also clearly shows an inflection on the $\pi$ curve at the second monolayer. Taking the $\pi$ value at the inflection point $(18 \mathrm{~mJ} /$ $\mathrm{m}^{2}$ ) and the $\gamma_{\mathrm{g}}^{\mathrm{d}}=25 \mathrm{~mJ} / \mathrm{m}^{2}$ one can calculate from Eq. [4] the polar component $\gamma_{\mathrm{g}}^{\mathrm{p}}$ equal to $80 \mathrm{~mJ} / \mathrm{m}^{2}$. This value is in excellent agreement with that obtained from ellipsometry, $80 \mathrm{~mJ} / \mathrm{m}^{2}$, thus giving support for the usefulness of both methods employed for solid surface free energy determination, despite the rather large final uncertainties involved.

Table III summarizes the film pressures and surface free energy components of glass determined both ellipsometrically and electrokinetically.

\section{DISCUSSION}

In this paper we demonstrated a good correspondence between the dispersion and polar surface free energy components of glass, obtained by means of ellipsometrically and electrokinetically obtained adsorption isotherms.

Both techniques yielded a high glass surface free energy between 106 and $112 \mathrm{~mJ} / \mathrm{m}^{2}$, which is rather similar to the value obtained from contact angles $\left(109 \mathrm{~mJ} / \mathrm{m}^{2}\right)$, while taking spreading pressures into account $(14,21-$ 23), but which is however considerably lower than that obtained from contact angles when the ellipsometrically derived spreading pressure is inserted in the proper equation (21), yielding $242 \mathrm{~mJ} / \mathrm{m}^{2}$. Fowkes (25) showed that the dispersion surface free energy component of bare quartz equals $76 \mathrm{~mJ} / \mathrm{m}^{2}$, but that one monolayer only of physically adsorbed water reduces this value to approximately $30 \mathrm{~mJ} /$

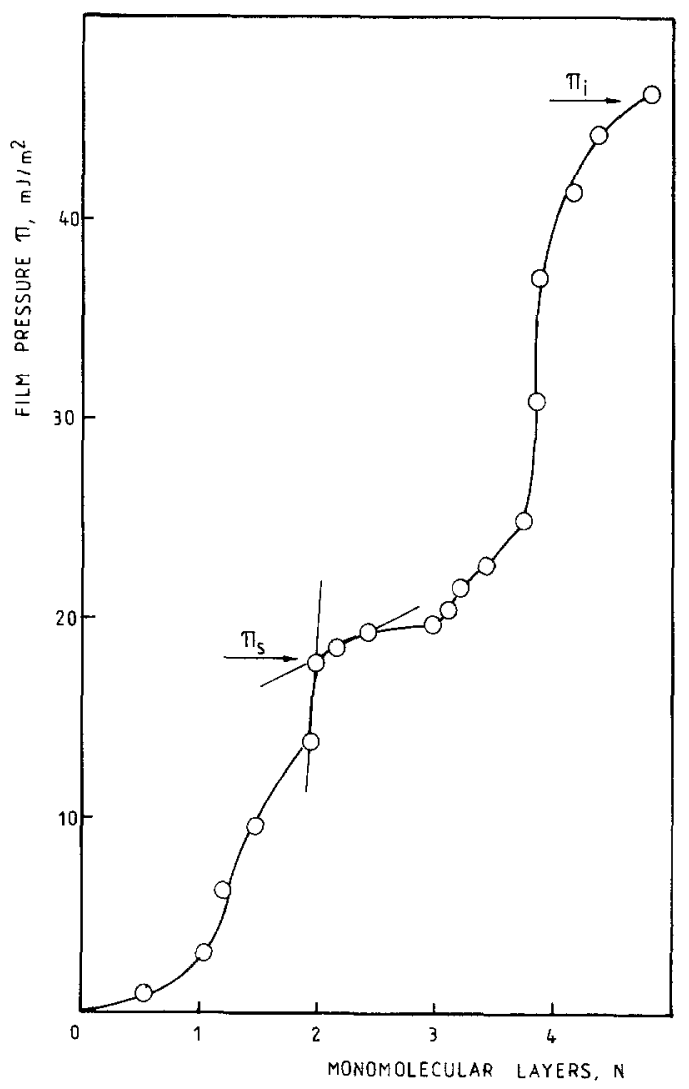

FIG. 5. $n$-Hexanol film pressure $( \pm 7 \%)$ on glass as a function of the number of calculated monomolecular layers determined from zeta potentials. $\pi_{i}$ is the point of immersional wetting.

Journal of Colloid and Interface Science, Vol. 132, No. 1, October 1, 1989 
TABLE III

Summary of Ellipsometrically and Electrokinetically Determined Spreading Pressures and Surface Free Energy Components of Glass

\begin{tabular}{ccc}
\hline Parameter & Ellipsometry & Electrokinetics \\
\hline $\begin{array}{l}\text { Spreading pressure } \\
\text { for water }\end{array}$ & $35 \pm 5$ & Not determined \\
$\begin{array}{c}\text { Spreading pressure } \\
\text { for } n \text {-octane }\end{array}$ & $10 \pm 1$ & $3.5 \pm 0.5$ \\
$\begin{array}{c}\text { Spreading pressure } \\
\text { for } n \text {-hexanol }\end{array}$ & Not determined & $18 \pm 2$ \\
$\begin{array}{c}\text { Dispersion surface } \\
\text { free energy } \\
\text { component }\end{array}$ & $32 \pm 6$ & $25 \pm 5$ \\
$\begin{array}{c}\text { Polar surface free } \\
\text { energy } \\
\text { component }\end{array}$ & $80 \pm 16$ & $80 \pm 16$ \\
\hline
\end{tabular}

Note. All data in $\mathrm{mJ} / \mathrm{m}^{2}$.

$\mathrm{m}^{2}$. Furthermore it has been suggested that, one monolayer of water can decrease the polar surface free energy component of quartz to 90 $\mathrm{mJ} / \mathrm{m}^{2}(26,27)$. Since the values obtained in this study for both the dispersion and the polar surface free energy components (see Table III) point to the presence of such a preadsorbed water layer, we believe that in this paper both techniques have yielded acceptable and realistic values for both the polar and the dispersion surface free energy components of glass.

Although it is likely that the surface properties of crushed and ground glass grains are not directly comparable with those of an intact glass surface due to, e.g., compositional differences, differences in roughness, or possible contamination of the particles during grinding, we did not detect noticeable differences in surface energetics from a comparison of the two techniques employed. This probably indicates that possible differences are leveled out very easily by exposure to atmospheric conditions.

Comparing the $\pi$ values for $n$-octane obtained from ellipsometry (Fig. 1) with those from the zeta potential method (Fig. 4) it can be seen that at three calculated monolayers the results are similar, $9-11 \mathrm{~mJ} / \mathrm{m}^{2}$. However, changes of $\pi$ versus surface coverage are somewhat different. The inflections are much more distinct on the curves obtained from zeta potentials (Fig. 4).

It is worth mentioning that in general inflections on $\pi$ values versus area isotherms can be detected directly for an insoluble film on a liquid surface which arises from film collapse and successive layer formation. This process is of course connected with free energy changes $(19,28-30)$. It supports the above idea of interpreting inflections appearing on film pressure versus surface coverage curves in solid/ film-water systems or solid/film-vapor systems in which the inflections cannot be determined directly. The results obtained in this paper point to the conclusion that properties of a liquid film on a solid surface are similar to those of an insoluble film on a liquid surface with regard to the energy changes occurring.

Furthermore the correspondence between the dispersion and the polar surface free energy components of glass obtained by two completely independent techniques gives confidence to the approaches employed. Although we have demonstrated in the past (21) that the ellipsometric technique can be used to determine spreading pressures of water and $n$ propanol on polymeric substrata, experiments are now under way to establish whether ellipsometrically and electrophoretically measured dispersion and polar surface free energy components correspond for polymeric substrata as well.

\section{REFERENCES}

1. Spelt, J. K., and Neumann, A. W., Langmuir 3, 588 (1987).

2. Wu, S., J. Polym. Sci. 34, 19 (1971).

3. Fowkes, F. M., J. Colloid Interface Sci. 64, 36 (1978).

4. Fowkes, F. M., Ind. Eng. Chem. 56, 40 (1964).

5. Zettlemoyer, A. C., in "Hydrophobic Surfaces" (F. M. Fowkes, Ed.), p. 1. Academic Press, New York/London, 1969.

6. Van Oss, C. J., Good, R. J., and Chaudhury, M. K., Sep. Sci. Technol. 22, 1 (1986).

7. Owens, D. K., and Wendt, R. C., J. Appl. Polym. Sci. 13, 1741 (1969).

8. Wu, S., J. Phys. Chem. 74, 632 (1970).

9. Good, R. J., and Elbing, E., Ind. Eng. Chem. 62, 54 (1970). 
10. Jańczuk, B., and Białopiotrowicz, T., J. Colloid Interface Sci., 128, 1 (1989).

11. Busscher, H. J., Pelt, A. W. J. van, de Jong, H. P. and Arends, J., J. Colloid Interface Sci. 81, 75 (1981).

12. Neumann, A. W., Adv. Colloid Surf. Sci. 4, 105 (1974).

13. Jańczuk, B., Chibowski, E., and Białopiotrowicz, T., J. Colloid Interface Sci. 102, 533 (1984).

14. Billinski, B., and Chibowski, E., Powder Technol. 35, 39 (1983).

15. Jańczuk, B., Chibowski, E., and Staszczuk, P., J. Colloid Interface Sci. 96, 1 (1983).

16. Chibowski, E., and Waksmundzki, A., J. Colloid Interface Sci. 66, 213 (1978).

17. Chibowski, E., and Hołysz, L., J. Colloid Interface Sci. 81, 8 (1981).

18. Chibowski, E., J. Colloid Interface Sci. 86, 567 (1982).

19. Chibowski, E., and Hołysz, L., J. Colloid Interface Sci. 112, 15 (1986).

20. Tadros, M. E., Hu, P., and Adamson, A. W., J. Colloid Interface Sci. 49, 184 (1974).
21. Busscher, H. J., Kip, G. A. M., van Silfhout, A., and Arends, J., J. Colloid Interface Sci. 114, 307 (1986).

22. Busscher, H. J., de Jong, H. P., and Arends, J., Mater. Chem. Phys. 17, 553 (1987).

23. Busscher, H. J., and Pelt, A. W. J. van, J. Mater. Sci. Lett. 6, 815 (1987).

24. Busscher, H. J., Pelt, A. W. J. van, de Jong, H. P., and Arends, J., J. Colloid Interface Sci. 95, 23, (1983).

25. Fowkes, F. M., J. Colloid Interface Sci. 28, 493 (1968).

26. Jańczuk, B., Staszczuk, P., and Chibowski, E., Mater. Chem. Phys. 12, 469 (1985).

27. Jańczuk, B., Przem. Chem. 61, 468 (1982).

28. Adamson, A. W., "Physical Chemistry of Surfaces," p. 124. Interscience, New York, 1982.

29. Malcolm, B. R., in "Progress in Surface and Membrane Science" (J. F. Danielli, M. D. Rosenberg, and D. A. Cadenhead, Eds.), Vol. 7, p. 200. Academic Press, New York/London, 1973.

30. Rayss, J., J. Colloid Interface Sci. 91, 376 (1983). 